\title{
СОВРЕМЕННЫЕ МЕТОДЫ ХИРУРГИЧЕСКОГО ЛЕЧЕНИЯ У ПАЦИЕНТОВ С ЭНДОКРИННОЙ ОФТАЛЬМОПАТИЕЙ
}

\author{
Левченко О.В., Григорьев А.Ю., Каландари А.А., Кутровская Н.Ю. \\ МГМСУ им. А.И. Евдокимова, Москва
}

ЦЕЛЬ: улучшить результаты хирургического лечения пациентов с эндокринной офтальмопатией.

МАТЕРИАЛЫ И МЕТОДЫ: В НеЙроХирУргичесКОМ отделениИ КМЦ МГМСУ им. А.И. ЕвдокИмова прооперировано 24 пациентов (32 орбиты) с эндокринной офтальмопатией липогенной, миогенной или сме-

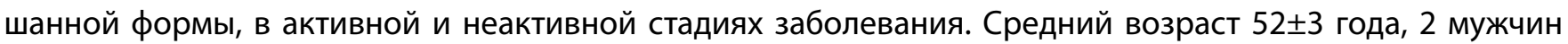
и 22 женщины. Выполняли полное офтальмологическое обследование, анализ крови на ТТГ, своб. Т4, АТ к рТТГ, АТ к ТПО, а также РКТ орбит. Экзофтальму 5 пациентов составлял от 7 до 10 мм, у 13 пациентов от 4 до 6 мм. Липэктомия с латеральной орбитотомией выполнена 5 пациентам с липогенной формой ЭОП, «сбалансированная» орбитотомия с применением нейронавигации - 13 пациентам с миогенной и смешанной формой ЭОП. Экстренную эндоскопическую трансназальную орбитотомию медиальной стенки и декомпрессию зрительного нерва провели 6 пациентам (9 орбит) с выраженным снижением остроты зрения от 0,1 до p.l. certa при прогрессирующей оптической нейропатии в активной стадии ЭОП.

PEЗУЛЬТАТЫ: в послеоперационном периоде регресс экзофтальма при проведении «сбалансированной» орбитотомии составил от 8 до 10 мм, при липэктомия с латеральной орбитотомией этот показатель был от 4 до 5 мм. У пациентов с оптической нейропатией отмечено улучшение зрительных функций после проведения декомпрессии зрительного нерва. Отмечали повышение остроты зрения в первые сутки на 0,1, при последующих наблюдениях - на 0,4-0,5, расширение периферических полей зрения. После эндоскопической трансназальной декомпрессии зрительного нерва, пациентам выполняли «сбалансированную» орбитотомию, реконструктивные операции на экстраокулярных мышцах, коррекцию ретракции верхнего века.

ВЫВОдЫ: миниинвазивные трансорбитальные доступы с использованием нейронавигационной системы позволяют осуществить подход ко всем стенкам глазницы трансконъюнктивально, выполнить костную декомпрессию орбиты в полном объеме и добиться хороших косметических и функциональных результатов. Эндоскопическая трансназальная декомпрессия зрительного нерва является эффективным методом лечения оптической нейропатии в активной стадии эндокринной офтальмопатией, направлена на предотвращение слепоты у пациентов с выраженным снижением остроты зрения. 